Original article

\title{
Evaluation of Nutritional Practices in the Critical Care patient (The ENPIC study): Does nutrition really affect ICU mortality?
}

Lluís Servia-Goixart a, b, Juan C. Lopez-Delgado c, d, *, Teodoro Grau-Carmona e, f, Javier Trujillano-Cabello $^{\text {a, b}}$, M Luisa Bordeje-Laguna ${ }^{g}$, Esther Mor-Marco ${ }^{g}$, Esther Portugal-Rodriguez ${ }^{\mathrm{h}}$, Carol Lorencio-Cardenas ${ }^{\mathrm{i}}$, Juan C. Montejo-Gonzalez e, f, Paula Vera-Artazcoz ${ }^{j}$, Laura Macaya-Redin ${ }^{k}$, Juan Francisco Martinez-Carmona ${ }^{1}$, Rayden Iglesias-Rodriguez ${ }^{\mathrm{m}}$, Diana Monge-Donaire ${ }^{\mathrm{n}}$, José L. Flordelis-Lasierra ${ }^{\mathrm{o}}$, Beatriz Llorente-Ruiz ${ }^{\mathrm{p}}$, Eva M. Menor-Fernández ${ }^{\mathrm{q}}$, Itziar Martínez de Lagrán ${ }^{\mathrm{r}}$, Juan C. Yebenes-Reyes ${ }^{\mathrm{r}}$, on behalf of the ENPIC Study Investigators ${ }^{1}$

${ }^{\mathrm{a}}$ Hospital Universitari Arnau de Vilanova, Intensive Care Department, Av. Alcalde Rovira Roure, 80, 25198, Lleida, Spain

${ }^{\mathrm{b}}$ IRBLLeida (Institut de Recerca Biomèdica de Lleida Fundació Dr. Pifarré; Lleida Biomedical Research Institute's Dr. Pifarré Foundation, Av. Alcalde Rovira Roure, 80, 25198, Lleida, Spain

${ }^{\mathrm{c}}$ Hospital Universitari de Bellvitge, Intensive Care Department, C/Feixa Llarga s/n, 08907, L'Hospitalet de Llobregat, Barcelona, Spain

${ }^{\mathrm{d}}$ IDIBELL (Institut d'Investigació Biomèdica Bellvitge; Biomedical Investigation Institute of Bellvitge, Av. de la Granvia, 199, 08908 L'Hospitalet de Llobregat, Barcelona, Spain

${ }^{\mathrm{e}}$ Hospital Universitario 12 de Octubre, Intensive Care Department, Av. de Córdoba s/n, 28041, Madrid, Spain

f $i+12$ (Instituto de Investigación Sanitaria Hospital 12 de Octubre; Research Institute Hospital 12 de Octubre), Av. de Córdoba s/n, 28041, Madrid, Spain

${ }^{g}$ Hospital Universitario Germans Trias i Pujol, Intensive Care Department, Carretera de Canyet, s/n, 08916, Badalona, Barcelona, Spain

${ }^{\text {h }}$ Hospital Clínico Universitario de Valladolid, Intensive Care Department, Av. Ramón y Cajal, 3, 47003, Valladolid, Spain

${ }^{\mathrm{i}}$ Hospital Universitari Josep Trueta, Intensive Care Department, Av. de França, s/n, 17007, Girona, Spain

${ }^{j}$ Hospital de la Santa Creu i Sant Pau, Intensive Care Department, C/ Sant Quintí, 89, 08041, Barcelona, Spain

${ }^{\mathrm{k}}$ Complejo Hospitalario de Navarra, Intensive Care Department, C/ Irunlarrea, E, 31008, Pamplona, Navarra, Spain

${ }^{1}$ Hospital Regional Universitario Carlos Haya, Intensive Care Department, Av. de Carlos Haya, 84, 29010, Málaga, Spain

${ }^{\mathrm{m}}$ Hospital General de Granollers, Intensive Care Department, C/ Francesc Ribas, s/n, 08402, Granollers, Barcelona, Spain

${ }^{\mathrm{n}}$ Hospital Virgen de la Concha, Intensive Care Department, Av. de Requejo, 35, 49022, Zamora, Spain

${ }^{\circ}$ Hospital Universitario Severo Ochoa, Intensive Care Department, Av. de Orellana, s/n, 28911, Leganés, Madrid, Spain

${ }^{\mathrm{p}}$ Hospital Univeristario Príncipe de Asturias, Intensive Care Department, Carr. de Alcalá, s/n, 28805, Meco, Madrid, Spain

${ }^{\mathrm{q}}$ Hospital Alvaro Cunqueiro, Intensive Care Department, C/ Clara Campoamor, 341, 36203, Vigo, Pontevedra, Spain

${ }^{\mathrm{r}}$ Hospital de Mataró, Intensive Care Department, Carr. Cirera, 230, 08304, Mataró, Barcelona, Spain

\section{A R T I C L E I N F O}

Article history:

Received 3 November 2021

Accepted 8 November 2021

\section{Keywords:}

Nutritional therapy

Intensive care unit

\section{S U M M A R Y}

Background \& aims: The importance of artificial nutritional therapy is underrecognized, typically being considered an adjunctive rather than a primary therapy. We aimed to evaluate the influence of nutritional therapy on mortality in critically ill patients.

Methods: This multicenter prospective observational study included adult patients needing artificial nutritional therapy for $>48 \mathrm{~h}$ if they stayed in one of 38 participating intensive care units for $\geq 72 \mathrm{~h}$ between April and July 2018. Demographic data, comorbidities, diagnoses, nutritional status and therapy

Abbreviations: EN, Enteral nutrition; ENPIC, Evaluation of Nutritional Practices in the Critical Care; ICU, Intensive care unit; LOS, Length of stay; NUTRIC, Nutrition Risk in

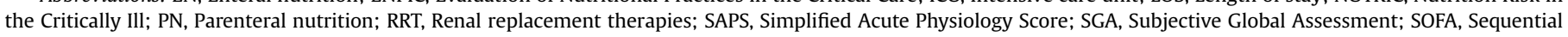
Organ Failure Assessment.

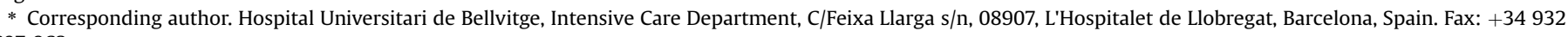
607963.

E-mail addresses: Iserviag@gmail.com (L. Servia-Goixart), juancarloslopezde@hotmail.com (J.C. Lopez-Delgado), teodoro.grau@salud.madrid.org (T. Grau-Carmona),

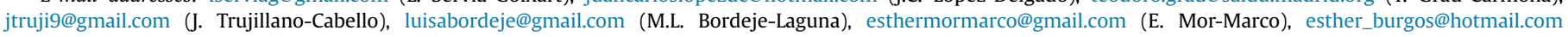

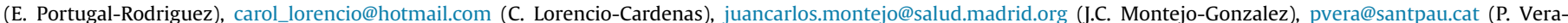

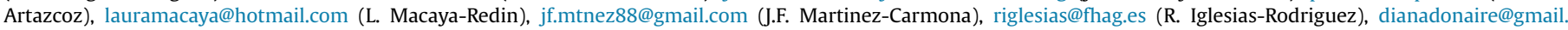

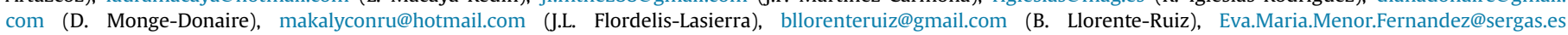
(E.M. Menor-Fernández), itziarmz@hotmail.com (I. Martínez de Lagrán), juancarlos.yebenes@gmail.com (J.C. Yebenes-Reyes).

${ }^{1}$ ENPIC Study Investigators. See acknowledgement section. enpicstudy@gmail.com 
Enteral nutrition

Parenteral nutrition

Mortality (type and details for $\leq 14$ days), and outcomes were registered in a database. Confounders such as disease severity, patient type (e.g., medical, surgical or trauma), and type and duration of nutritional therapy were also included in a multivariate analysis, and hazard ratios (HRs) and 95\% confidence intervals (95\% CIs) were reported.

Results: We included 639 patients among whom 448 (70.1\%) and 191 (29.9\%) received enteral and parenteral nutrition, respectively. Mortality was 25.6\%, with non-survivors having the following characteristics: older age; more comorbidities; higher Sequential Organ Failure Assessment (SOFA) scores (6.6 \pm 3.3 vs $8.4 \pm 3.7 ; P<0.001)$; greater nutritional risk (Nutrition Risk in the Critically Ill [NUTRIC] score: $3.8 \pm 2.1$ vs $5.2 \pm 1.7 ; P<0.001)$; more vasopressor requirements $(70.4 \%$ vs $83.5 \% ; P=0.001)$; and more renal replacement therapy $(12.2 \%$ vs $23.2 \% ; P=0.001)$. Multivariate analysis showed that older age (HR: 1.023; 95\% CI: 1.008-1.038; $P=0.003$ ), higher SOFA score (HR: 1.096; 95\% CI: 1.036-1.160; $P=0.001$ ), higher NUTRIC score (HR: 1.136; 95\% CI: 1.025-1.259; $P=0.015$ ), requiring parenteral nutrition after starting enteral nutrition (HR: 2.368; 95\% CI: $1.168-4.798 ; P=0.017$ ), and a higher mean $\mathrm{Kcal} / \mathrm{Kg} / \mathrm{day}$ intake (HR: 1.057; 95\% CI: 1.015-1.101; $P=0.008$ ) were associated with mortality. By contrast, a higher mean protein intake protected against mortality (HR: $0.507 ; 95 \% \mathrm{CI}: 0.263-0.977 ; P=0.042$ ).

Conclusions: Old age, higher organ failure scores, and greater nutritional risk appear to be associated with higher mortality. Patients who need parenteral nutrition after starting enteral nutrition may represent a high-risk subgroup for mortality due to illness severity and problems receiving appropriate nutritional therapy. Mean calorie and protein delivery also appeared to influence outcomes.

Trial registration: ClinicaTrials.gov NCT: 03634943.

(C) 2021 The Author(s). Published by Elsevier Ltd on behalf of European Society for Clinical Nutrition and Metabolism. This is an open access article under the CC BY-NC-ND license (http://creativecommons.org/ licenses/by-nc-nd/4.0/).

\section{Introduction}

The inflammatory response to surgery, trauma, or any severe medical condition causes metabolic disturbances (e.g., protein catabolism) in patients admitted to intensive care units (ICUs) [1]. In conjunction, difficulty achieving adequate nutritional targets in clinical practice may expose patients to nutritional risk or a worsening of preexisting malnutrition [2-4], both of which are associated with a higher incidence of complications and mortality [5-7]. Nutritional therapy not only provides the substrates to preserve organ function but also helps modulate the inflammatory response, optimizes the metabolic status, and ultimately provides substantial benefit in terms of survival and outcome $[5,6]$. However, some trials have reported harmful effects, and the beneficial effect of nutrition on mortality is underrecognized due to these controversial results [8].

It is not always possible to provide evidence of the benefit of nutrition in ICUs. Several factors related to nutritional therapy, such as the macronutrient dose (i.e., calories and proteins), delivery route (i.e., enteral [EN] and parenteral nutrition [PN]), and initiation time, with each having the potential to affect treatment effectiveness and explain the lack of positive results in some trials [5,6]. EN is the preferred delivery route for patients in ICU, but there is huge variation in how nutritional therapy is provided clinically. Moreover, difficulty persists in meeting the nutritional targets established in clinical practice guidelines, even in randomized control trials (RCTs) [9-15]. Thanks to technical advances and lower rates of associated infection, PN is now considered as safe as EN and may provide optimal delivery of nutrients [9]. Another issue that affects the perceived benefit of nutritional therapy is its duration during the ICU stay. The impact of nutrition may seem less important in those with shorter stays, lower nutritional risks, and less severe critical illness $[5,6,16]$. Thus, we must consider all these factors in clinical ICU settings when evaluating the impact of nutrition on mortality, especially those associated with the delivery route and duration of therapy.

The primary aim of this study was to estimate the effect on mortality of the different features of artificial nutrition therapy during ICU stays (e.g., time of initiating nutritional support, mean energy intake, and mean protein intake). A secondary objective was to evaluate if mortality was affected by the delivery route (e.g., EN, PN, or both).

\section{Material and methods}

\subsection{Study population}

This multicenter prospective observational study was conducted at 38 ICUs across Spain between April and July 2018. Consecutive adult patients (age $>18$ years) needing artificial nutritional therapy for $>48 \mathrm{~h}$ and staying in ICU for $\geq 72 \mathrm{~h}$ were included. We excluded patients admitted to ICU for postoperative recovery or ICU monitoring without needing specific therapy for organ support (e.g., vasopressors or non-invasive mechanical ventilation) and those able to be fed orally.

Patients in the present study were included from the Evaluation of Nutritional Practices in the Critical Care (ENPIC) study cohort. This research reflects a planned analysis and endpoint of this study (ClinicalTrials.gov Identifier: NCT03634943). The observational design meant that we made no attempt to influence general ICU care or the nutritional approach. However, to evaluate eligibility, participating hospitals were asked to provide information about their clinical nutrition practices and the degree of adherence to current guidelines (e.g., presence of a nutritional protocol or the involvement of a health care provider specializing in artificial nutritional support) [9].

\subsection{Ethics}

A central Institutional Ethics Committee (Comité d'Ètica i Assajos Clínics de Hospital Universitari de Bellvitge; Barcelona, Spain) approved the study (no. PR401/17), and the need for informed consent was waived due to the observational design.

\subsection{Data collection and definitions}

Data were extracted prospectively from the medical records of each patient and hosted in a centralized database for analysis (REDCap ${ }^{\circledR}$ electronic data at the Hospital Arnau de Vilanova, Lleida, Spain). The entered data were cleaned from August to November 
2018, and data queries were sent back to the participating investigators for verification, after which we performed a second check and closed the database in May 2020. The following general data were collected: demographics; diagnoses and comorbidities; nutritional assessment, using the Subjective Global Assessment (SGA) and modified Nutrition Risk in the Critically Ill (mNUTRIC) scores (without the IL-6 component); and the Acute Physiology and Chronic Health Evaluation (APACHE) II score, the Simplified Acute Physiology Score (SAPS) II, and the Sequential Organ Failure Assessment (SOFA) score on ICU admission.

Details of nutritional therapy were also collected: the time nutritional therapy was initiated, the mean energy and protein intakes until ICU discharge or for a maximum of 14 days, and ENrelated complications during their ICU stay (i.e., residual gastric volume, diarrhea, vomiting, aspiration, and mesenteric ischemia), as defined in the current literature [17]. Non-nutritional calories (dextrose infusion and propofol) were considered for the mean energy intake calculations. Enteral protein supplementation was also recorded for mean protein intake calculation.

Outcomes were recorded during ICU stays, including details of hemodynamic support, renal replacement therapies (RRT), mechanical ventilation, respiratory tract infection, and catheterrelated infection. ICU and hospital mortality were followed-up for 28 days. The type of nutritional therapy was classified by the route of administration as either EN, PN, or both. The latter was classified into two subgroups based on the initial route of nutrition: EN-PN received EN initially and $\mathrm{PN}-\mathrm{EN}$ received $\mathrm{PN}$ initially. The route was chosen by the treating medical ICU team based on the clinical indication.

To evaluate the estimate effect of different characteristics of nutrition therapy during ICU stay, we compared subgroups based on 28-day mortality. We also compared the differences among the different types of artificial nutritional therapies by administration route. The duration of nutritional therapy was included in all analysis to add a time perspective.

\subsection{Statistical analyses}

Data are expressed as means and standard deviations, median (interquartile ranges), or numbers and percentages, as appropriate. Analysis of variance was used to compare differences in characteristics between subgroups, and the Bonferroni post-hoc test was used to determine significant differences in the pairwise comparisons. The statistical analyses were conducted using IBM SPSS version 20.0 (IBM Corp., Armonk, NY, USA), and two-tailed P-values

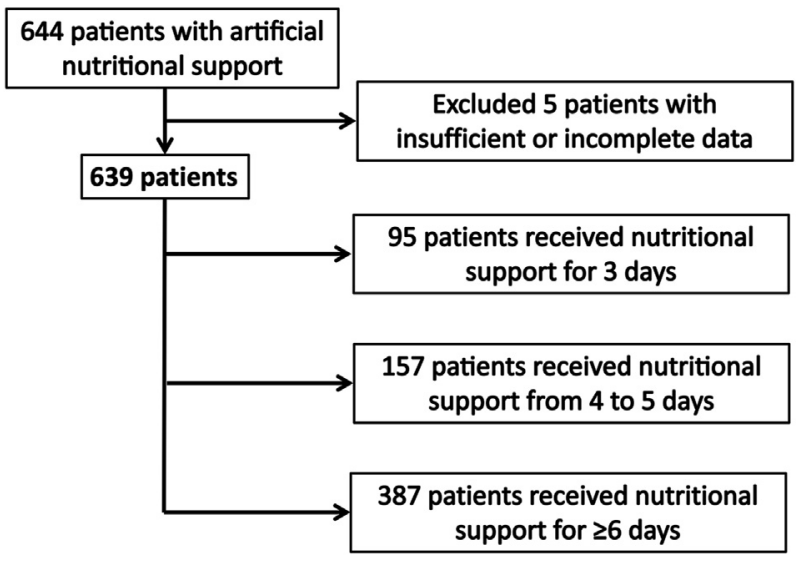

Fig. 1. Study flow chart.
$<0.05$ were considered statistically significant, unless stated otherwise.

The Mann-Whitney $U$ test or the two-sample t-test were used to compare between groups, as appropriate, and the $\chi^{2}$ test was used to evaluate categorical prognostic factors in the univariate analysis. In all cases, the Kolmogorov-Smirnov test and D'Agostino-Pearson omnibus normality test were used to check the normality of the population distribution. Survival analysis was conducted using the Kaplan-Meier estimator for each subgroup (log-rank test). Subsequent multivariate analysis was conducted using an adjusted multiple stepwise Cox regression analysis to assess the 28-day mortality. Variables were included in the initial model if they had a P-value $<0.2$ and were deemed suitable by the investigators based on careful consideration of confounding. Investigators selected variables based on current knowledge and

Table 1

Characteristics, nutritional support, and outcomes of the patients admitted in the ICU population.

\begin{tabular}{|c|c|c|}
\hline & & $\begin{array}{l}\text { All patients } \\
(N=639)\end{array}$ \\
\hline \multicolumn{3}{|c|}{ Baseline characteristics \& comorbidities } \\
\hline \multicolumn{2}{|l|}{ Mean age (years) } & $61.8 \pm 15$ \\
\hline \multicolumn{2}{|l|}{ Sex (male) } & $432(67.6 \%)$ \\
\hline \multicolumn{2}{|l|}{$\mathrm{BMI}\left(\mathrm{kg} \cdot \mathrm{m}^{-2}\right)$} & $27.7(27.4-28.4)$ \\
\hline \multicolumn{2}{|l|}{ Hypertension } & $281(44 \%)$ \\
\hline \multicolumn{2}{|l|}{ Diabetes mellitus } & $164(25.7 \%)$ \\
\hline \multicolumn{2}{|l|}{ COPD } & $110(17.2 \%)$ \\
\hline \multicolumn{2}{|l|}{ AMI } & $94(14.7 \%)$ \\
\hline \multicolumn{2}{|l|}{ Chronic Liver Disease } & $32(5 \%)$ \\
\hline \multicolumn{2}{|l|}{ Chronic Renal Failure } & $68(10.6 \%)$ \\
\hline \multicolumn{2}{|l|}{ Immunosuppression } & $73(11.4 \%)$ \\
\hline \multicolumn{2}{|l|}{ Neoplasia } & $137(21.4 \%)$ \\
\hline \multirow[t]{3}{*}{ Type of patient } & Surgery & $401(62.8 \%)$ \\
\hline & Medical & $72(11.2 \%)$ \\
\hline & Trauma & $166(26 \%)$ \\
\hline \multicolumn{2}{|l|}{ APACHE II } & $20(14-25)$ \\
\hline \multicolumn{2}{|l|}{ SAPS II } & $49 \pm 17.7$ \\
\hline \multicolumn{2}{|l|}{ SOFA (on admission) } & $7.1 \pm 3.5$ \\
\hline \multicolumn{2}{|c|}{ Patient with malnutrition (Based on SGA) } & $269(42.2 \%)$ \\
\hline \multicolumn{2}{|c|}{ mNUTRIC Score } & $4.2 \pm 2.1$ \\
\hline \multicolumn{2}{|c|}{ Patient at risk (Based on NUTRIC Score) } & $287(46 \%)$ \\
\hline \multicolumn{3}{|l|}{ Nutrition therapy } \\
\hline \multicolumn{2}{|c|}{ Time of initiation of nutrition therapy (h) } & $28(18-49)$ \\
\hline \multicolumn{2}{|c|}{ Early EN $(<48 \mathrm{~h})$} & $478(74.8 \%)$ \\
\hline \multicolumn{2}{|l|}{ Mean Kcal/kg/day ${ }^{\text {a }}$} & $15.7(15.3-16.3)$ \\
\hline \multicolumn{2}{|l|}{ Mean g protein $/ \mathrm{kg} /$ day ${ }^{a}$} & $0.81(0.79-0.84)$ \\
\hline \multirow[t]{6}{*}{ EN-related complications } & Any complication & $161(30.8 \%)$ \\
\hline & $\uparrow \mathrm{GRV}$ & $81(15.5 \%)$ \\
\hline & Diarrhoea & $51(9.8 \%)$ \\
\hline & Vomiting & $8(1.2 \%)$ \\
\hline & Aspiration & $1(0.2 \%)$ \\
\hline & Mesenteric ischemia & $9(1.7 \%)$ \\
\hline \multicolumn{3}{|l|}{ Outcomes } \\
\hline Mechanical ventilation & & $583(91.2 \%)$ \\
\hline Days on mechanical ventil & & $13(12-14)$ \\
\hline Vasoactive drug support & & $474(73.9 \%)$ \\
\hline RRT needs & & $97(15.1 \%)$ \\
\hline Respiratory tract infection & & $166(25.9 \%)$ \\
\hline Catheter-related infections & & $42(6.6 \%)$ \\
\hline Mean ICU LOS (days) & & $13(8-22)$ \\
\hline Mean hospital LOS (days) & & $27(16-45)$ \\
\hline 28-day Mortality & & $164(25.6 \%)$ \\
\hline
\end{tabular}

BMI: Body Mass Index; COPD: Chronic Obstructive Pulmonary Disease; AMI: Acute Myocardial Infarction; APACHE II: Acute Physiology and Chronic Health Disease Classification System II; SAPS: Simplified Acute Physiology Score; SOFA: Sequential Organ Failure Assessment; SGA: Subjective Global Assessment; mNUTRIC: modified Nutrition Risk in the Critically Ill; EN: Enteral Nutrition; PN: Parenteral Nutrition; RRT: Renal Replacement Therapy; ICU: Intensive Care Unit; LOS: Length of stay. Results are expressed as mean \pm standard deviation, percentage or median and interquartile range (first and third quartile).

a During the administration of the whole nutritional therapy or at least in the first 14 days of nutritional therapy. 
Table 2

Differences in baseline characteristics, nutrition therapy, and outcomes based on the type of route.

\begin{tabular}{|c|c|c|c|c|c|c|}
\hline & & $\begin{array}{l}\text { EN } \\
(63.4 \% ; n=405)\end{array}$ & $\begin{array}{l}\text { Total PN } \\
(18.2 \% ; \mathrm{n}=116)\end{array}$ & $\begin{array}{l}\text { EN-PN } \\
(6.7 \% ; n=43)\end{array}$ & $\begin{array}{l}\text { PN-EN } \\
(11.7 \% ; n=75)\end{array}$ & $p$ value \\
\hline \multicolumn{7}{|c|}{ Baseline characteristics \& comorbidities } \\
\hline \multicolumn{2}{|c|}{ Mean age (years) } & $60.8 \pm 15$ & $63.9 \pm 14$ & $60.2 \pm 14$ & $65.3 \pm 13$ & 0.04 \\
\hline \multicolumn{2}{|l|}{ Sex (male) } & $273(67.4 \%)$ & $72(62.1 \%)$ & $31(72.1 \%)$ & $56(74.7 \%)$ & 0.29 \\
\hline \multicolumn{2}{|l|}{ BMI $\left(\mathrm{kg} \cdot \mathrm{m}^{-2}\right)$} & $28.2 \pm 6.3$ & $27.1 \pm 5.5$ & $27.5 \pm 5.4$ & $26.3 \pm 4.7$ & 0.04 \\
\hline \multicolumn{2}{|l|}{ Hypertension } & $172(42.5 \%)$ & $55(47.4 \%)$ & $17(39.5 \%)$ & $37(49.3 \%)$ & 0.54 \\
\hline \multicolumn{2}{|l|}{ Diabetes mellitus } & $103(25.4 \%)$ & $28(24.1 \%)$ & $13(30.2 \%)$ & $20(26.7 \%)$ & 0.88 \\
\hline \multicolumn{2}{|l|}{ COPD } & $73(18 \%)$ & $15(12.9 \%)$ & $9(20.9 \%)$ & $13(17.3 \%)$ & 0.55 \\
\hline \multicolumn{2}{|l|}{ AMI } & $61(15.1 \%)$ & $17(14.7 \%)$ & $7(16.3 \%)$ & $9(12 \%)$ & 0.90 \\
\hline \multicolumn{2}{|l|}{ Chronic Liver Disease } & $22(5.4 \%)$ & $6(5.2 \%)$ & 0 & $4(5.3 \%)$ & 0.48 \\
\hline \multicolumn{2}{|l|}{ Chronic Renal Failure } & $42(10.4 \%)$ & $13(11.2 \%)$ & $3(7 \%)$ & $10(13.3 \%)$ & 0.74 \\
\hline \multicolumn{2}{|l|}{ Immunosuppression } & $42(10.4 \%)$ & $15(12.9 \%)$ & $6(14 \%)$ & $10(13.3 \%)$ & 0.74 \\
\hline \multicolumn{2}{|l|}{ Neoplasia } & $62(15.3 \%)$ & $45(38.8 \%)$ & $8(18.6 \%)$ & $22(29.3 \%)$ & $<0.001$ \\
\hline \multirow[t]{3}{*}{ Type of patient } & Medical & $289(71.4 \%)$ & $45(38.8 \%)$ & $31(72.1 \%)$ & $36(48.2 \%)$ & 0.01 \\
\hline & Trauma & $60(14.8 \%)$ & $2(1.7 \%)$ & $4(9.3 \%)$ & $6(8.2 \%)$ & 0.04 \\
\hline & Surgery & $56(13.8 \%)$ & $69(59.5 \%)$ & $8(18.6 \%)$ & $33(44 \%)$ & 0.07 \\
\hline \multicolumn{2}{|l|}{ APACHE II } & $20(15-25)$ & $19(14-24)$ & $20(17-28)$ & $20(15-27)$ & 0.014 \\
\hline \multicolumn{2}{|l|}{ SAPS II } & $48.3 \pm 17.4$ & $48 \pm 19$ & $52.1 \pm 17.1$ & $52.8 \pm 17.3$ & 0.16 \\
\hline \multicolumn{2}{|l|}{ SOFA (on admission) } & $7.1 \pm 6.1$ & $6.1 \pm 4$ & $8.7 \pm 3.6$ & $7.8 \pm 3.8$ & 0.01 \\
\hline \multicolumn{2}{|l|}{$\begin{array}{l}\text { Patient with malnutrition } \\
\text { (based on SGA) }\end{array}$} & $139(34.4 \%)$ & $68(58.1 \%)$ & $17(39.5 \%)$ & $45(60 \%)$ & $<0.001$ \\
\hline \multicolumn{2}{|l|}{ mNUTRIC Score } & $3.9 \pm 2.1$ & $4.3 \pm 1.9$ & $4.9 \pm 2.2$ & $4.8 \pm 1.8$ & 0.02 \\
\hline \multicolumn{7}{|l|}{ Nutrition therapy } \\
\hline \multicolumn{2}{|c|}{ Time of initiation of nutritional therapy (h) } & $28(19-48)$ & $28(17-63)$ & $41(24-71)$ & $24(14-47)$ & 0.06 \\
\hline \multicolumn{2}{|c|}{ Early EN $(<48 \mathrm{~h})$} & $310(76.8 \%)$ & $83(70.9 \%)$ & $27(61.4 \%)$ & $58(76.3 \%)$ & 0.11 \\
\hline \multicolumn{2}{|l|}{ Days on nutrition therapy } & $8(4-17)$ & $5(3-8)$ & $12(7-24)$ & $9(5-24)$ & $<0.001$ \\
\hline \multicolumn{2}{|l|}{ Mean $\mathrm{Kcal} / \mathrm{kg} /$ day ${ }^{\mathrm{a}}$} & $15.4 \pm 5.2$ & $19.2 \pm 7.3$ & $14.4 \pm 5.6$ & $20.9 \pm 5.7$ & $<0.001$ \\
\hline \multicolumn{2}{|l|}{ Mean $g$ protein/kg/day ${ }^{a}$} & $0.75 \pm 0.34$ & $0.94 \pm 0.43$ & $0.81 \pm 0.28$ & $1.1 \pm 0.35$ & $<0.001$ \\
\hline EN-related complications & Any complication & $89(21.9 \%)$ & NA & $29(67.4 \%)$ & $32(42.6 \%)$ & $<0.001$ \\
\hline & $\uparrow \mathrm{GRV}$ & $46(11.4 \%)$ & NA & $16(36.4 \%)$ & $19(25 \%)$ & $<0.001$ \\
\hline & Diarrhoea & $35(8.6 \%)$ & NA & $8(18.2 \%)$ & $8(10.5 \%)$ & 0.01 \\
\hline & Vomiting & $5(1.2 \%)$ & NA & $1(2.3 \%)$ & $2(2.6 \%)$ & 0.59 \\
\hline & Aspiration & 0 & NA & 0 & $1(1.3 \%)$ & 0.99 \\
\hline & Mesenteric ischemia & $3(0.7 \%)$ & NA & $4(9.1 \%)$ & $2(2.6 \%)$ & 0.01 \\
\hline Outcomes & & & & & & \\
\hline Mechanical ventilation & & $394(97.5 \%)$ & $79(68.1 \%)$ & $40(93 \%)$ & $70(93 \%)$ & $<0.001$ \\
\hline Days on mechanical ventila & & $13.2 \pm 13.8$ & $7.3 \pm 11$ & $21.5 \pm 18.3$ & $17.7 \pm 21.3$ & $<0.001$ \\
\hline Vasoactive drug support & & $296(73.3 \%)$ & $75(63.6 \%)$ & $33(75 \%)$ & 70 (92.1\%) & $<0.001$ \\
\hline RRT needs & & $41(10.1 \%)$ & $22(18.6 \%)$ & $18(40.9 \%)$ & $16(21.1 \%)$ & $<0.001$ \\
\hline Respiratory tract infection & & $102(25.2 \%)$ & $35(29.7 \%)$ & $8(18.2 \%)$ & $21(27.6 \%)$ & 0.48 \\
\hline Catheter-related infections & & $26(6.4 \%)$ & $12(10.2 \%)$ & $2(4.5 \%)$ & $3(3.9 \%)$ & 0.311 \\
\hline Mean ICU stay (days) & & $13(8-22)$ & $8(6-13)$ & $16(10-38)$ & $16(10-20)$ & $<0.001$ \\
\hline Mean hospital stay (days) & & $25(16-42)$ & $27(15-47)$ & $30(17-54)$ & $35(19-62)$ & 0.012 \\
\hline 28-day Mortality & & $101(24.9 \%)$ & $27(23.3 \%)$ & $16(37.2 \%)$ & 20() & 0.19 \\
\hline
\end{tabular}

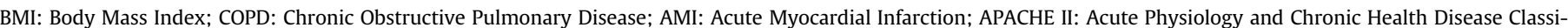

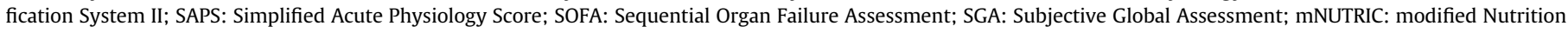

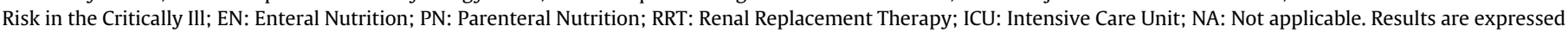
as mean \pm standard deviation, percentage or median and interquartile range (first and third quartile). Significant p values are written in bold.

a During the administration of the whole nutritional therapy or at least in the first 14 days of nutritional therapy.

literature perspective (Additional File 1: Figure S1) [18]. We used the change-in-estimates criterion and backward deletion with a $10 \%$ cutoff to eliminate variables from the final model. To avoid destabilizing the multivariate analyses, we tested for interactions between all introduced variables. We then adjusted for age, patient type (e.g., medical, surgical, or trauma), illness severity (e.g., APACHE score), length of nutritional therapy, and data for which there were significant differences in baseline characteristics between subgroups. This helped to avoid confounders and the influence of illness severity when analyzing outcomes.

\section{Results}

Data for 644 patients were included during the study, but due to the exclusion criteria and cases with incomplete data, the final sample comprised 639 patients (see Fig. 1). Their baseline characteristics are shown in Table 1, together with details of any nutritional therapy and clinical outcomes. A small proportion
( $\mathrm{n}=18 ; 2.8 \%$ ) of patients were underweight (Body Mass Index $\left.[\mathrm{BMI}]<18.5 \mathrm{~kg} \mathrm{~m}{ }^{-2}\right), 31 \%(\mathrm{n}=198)$ had normal BMI $\left(\mathrm{BMI} \geq 18.5-<25 \mathrm{~kg} \mathrm{~m}^{-2}\right)$, 39.1\% $(\mathrm{n}=250)$ had overweight $\left(\mathrm{BMI} \geq 25-<30 \quad \mathrm{~kg} \mathrm{~m}^{-2}\right), 17.9 \%(\mathrm{n}=114)$ were obese type I $\left(\mathrm{BMI} \geq 30-<35 \mathrm{~kg} \mathrm{~m}^{-2}\right), 5.3 \%(\mathrm{n}=34)$ were obese type II $\left(\mathrm{BMI} \geq 35-<40 \mathrm{~kg} \mathrm{~m}^{-2}\right)$ and $3.9 \%(\mathrm{n}=25)$ were morbidly obese $\left(\mathrm{BMI} \geq 40 \mathrm{~kg} \mathrm{~m}^{-2}\right)$.

Nutritional therapy was given for a mean duration of 8 days (4-16 days). Only 95 patients (14.8\%) received a short course ( $>48 \mathrm{~h}$ to $<72 \mathrm{~h}$ ) and only 157 (24.5\%) received an intermediate course ( $>72$ h to $<7$ days), whereas 387 (60.7\%) received a long course $(\geq 7$ days). We showed differences among these subgroups in organ failure severity at admission; type, characteristics, and complications of nutritional support; and ICU outcomes (Additional file 2: Table S1). Patients who received a short course of nutritional therapy received PN more frequently (hazard ratio [HR]: 1.966; 95\% Confidence Interval $[\mathrm{CI}]$ : $1.013-3.815 ; P=0.046)$ and exhibited lower 28-day mortality rates (HR: $0.458 ; 95 \% \mathrm{CI}: 0.236-0.890 ; P=0.021$ ). 

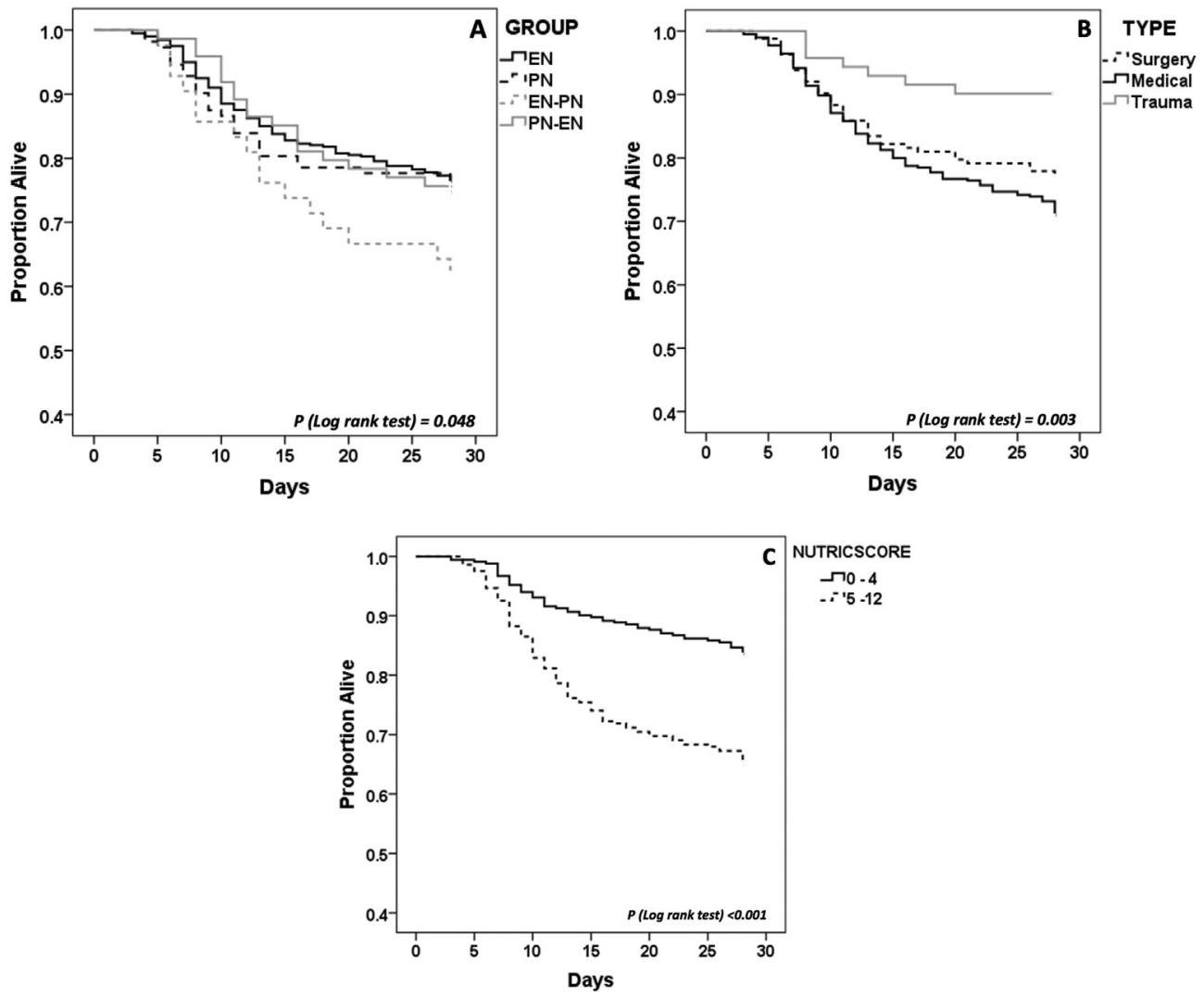

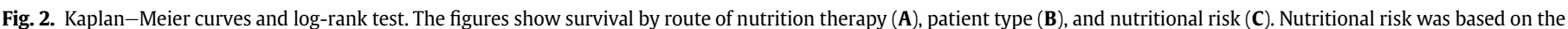
modified Nutrition Risk in the Critically Ill (mNUTRIC) score.

We classified patients into four subgroups by route of nutritional therapy administration (Table 2). Overall, 118 patients (18.4\%) received both EN and PN during ICU admission. Mesenteric ischemia was observed in 3 patients (2.5\%) who received PN alone, and all 3 were related to surgical complications.

We found differences in illness severity (e.g., SOFA and APACHE II), patient characteristics, patient type, mean calories achieved, and mean protein achieved during and after nutritional support. Adjusting for length of nutritional support, ICU scores, and nutritional risk scores (i.e., NUTRIC and SGA) as confounding factors, we found differences between subgroups. Compared with the PN group, patients receiving EN were more likely to be admitted for a medical indication (HR: 5.564; 95\% CI: 3.013-10.273; $P<0.001$ ) and to require invasive mechanical ventilation compared with the PN subgroup (HR: 6.950; 95\% CI: 1.120-7.766; $P<0.001$ ).

Compared with the EN-PN subgroup, the EN subgroup performed better during early EN support (HR: 2.313; 95\% CI: 1.130-4.763; $P=0.022)$ and had fewer EN-related complications (HR: 0.264; 95\% CI: 0.133-0.527; $P<0.001$ ). Compared with PN-EN subgroup, the EN subgroup also needed less vasoactive drug support (HR: $0.234 ; 95 \% \mathrm{CI}: 0.089-0.612 ; P=0.003$ ) and suffered lower EN-related complication (HR: 0.469; 95\% CI: 0.259-0.850; $P=0.013)$. Compared with the EN-PN subgroup, the PN subgroup had a lower 28-day mortality rate (HR: 0.321; 95\% CI: 0.134-0.335; $P=0.02)$. Compared with the PN-EN subgroup, the EN-PN had more EN-related complications (HR: 2.983; 95\% CI: 1.102-8.017; $P=0.032$ ) and higher 28-day mortality (HR: 3.149; 95\% CI: 1.055-9.398; $P=0.04)$. Indeed, the EN-PN subgroup showed the worst 28-day survival among all subgroups during ICU admission (Fig. 2A). Despite not achieving statistical significance, patients who received EN first line (i.e., the EN and EN-PN subgroups) received less mean calorie and protein delivery than patients in whom PN was started initially (i.e., the PN and PN-EN subgroups).

There were also differences between groups by survival, with non-survivors having more comorbidities and showing greater nutritional risk, illness severity, and need for RRT and vasopressor support (Table 3). Non-survivors also had a higher incidence of mesenteric ischemia and shorter ICU stays, whereas survivors received more protein and fewer calories while receiving nutritional support (or for 14 days). When we analyzed the 28-day survival, we found that patients admitted because of trauma (11.3\%) showed a trend toward better survival than those admitted with either surgical (23.5\%) or medical (29.4\%) indications $(P=0.003$; Fig. 2B). Patients with higher nutritional risk also showed poorer survival, with survival rates of $87 \%$ and $68 \%$ for mNUTRIC scores of $0-4$ and $>4$, respectively $(P<0.001$; Fig. $2 C)$. No analysis revealed an association by the time of starting nutritional therapy.

In the multivariate analysis, we adjusted for confounders such as the nutritional therapy duration, ICU score, patient type, and nutritional risk score (i.e., mNUTRIC and SGA). This revealed that older age and higher mNUTRIC and SOFA scores at ICU admission were positively associated with the 28-day mortality. The EN-PN subgroup also showed a positive association with 28-day mortality. A higher mean calorie delivery during nutritional therapy was associated with a higher mortality, whereas a higher mean protein delivery was protective against higher mortality (Table 4).

\section{Discussion}

The results of the present study have identified several nutritional - and nutritional-related - factors that may affect short-term mortality. Some of these factors, such as having a higher SOFA score 
Table 3

Differences in baseline characteristics, nutrition therapy, and outcomes between survivors and non-survivors.

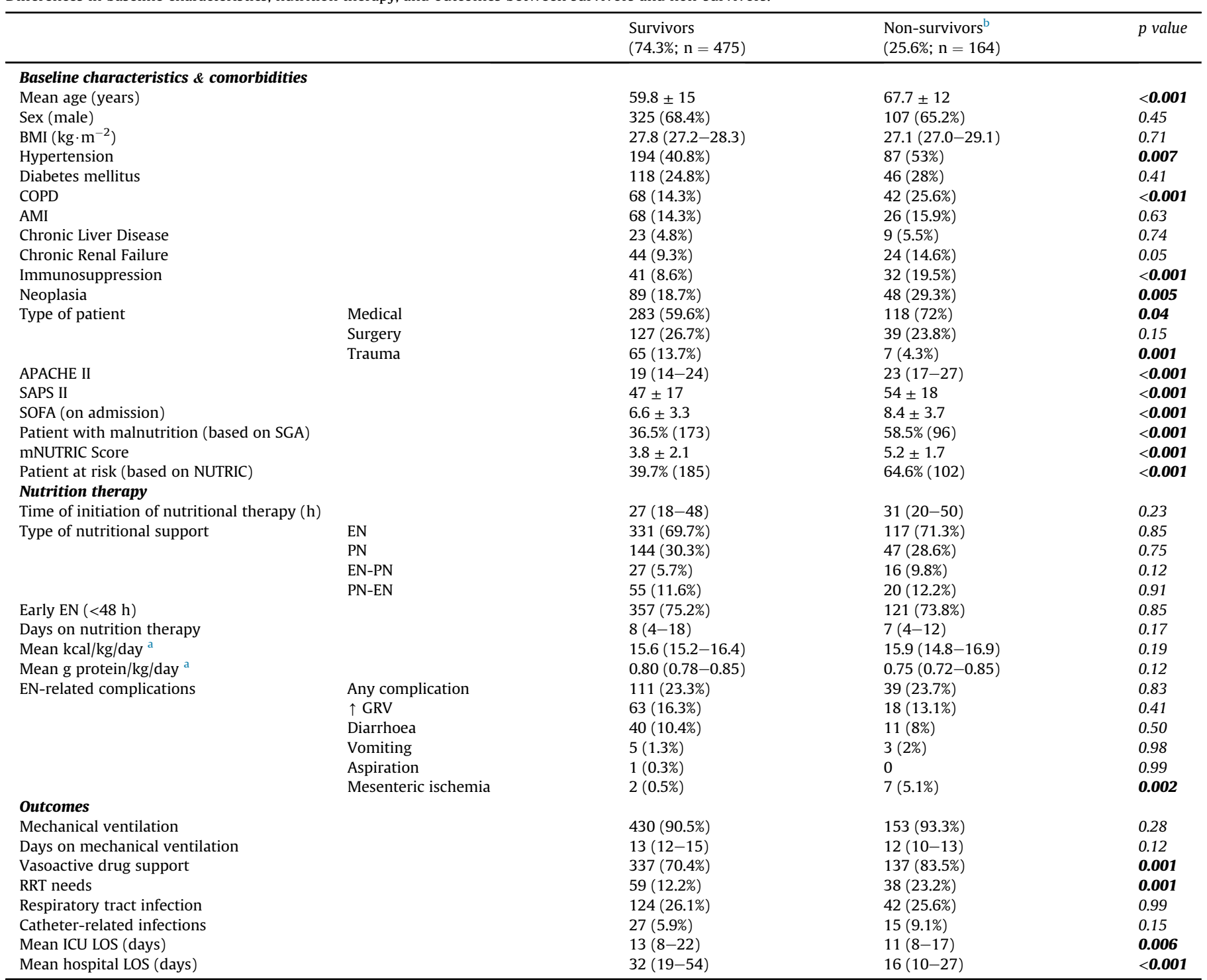

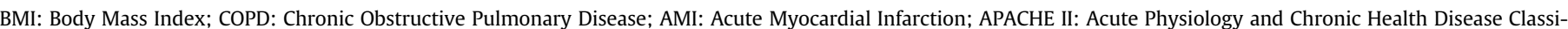

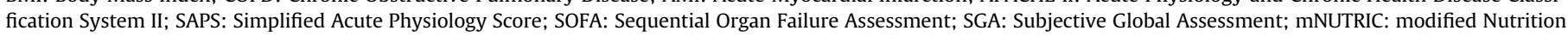

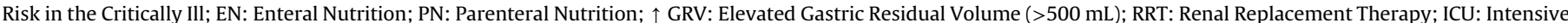

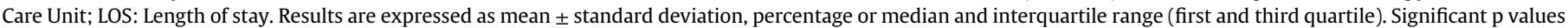
are written in bold.

a During the administration of the whole nutritional therapy or at least in the first 14 days of nutritional therapy.

b Based on 28-day mortality.

or higher age, are logically associated with mortality. However, the roles of the mNUTRIC score, the need for PN after starting EN, and a higher mean caloric intake during nutritional therapy associated with mortality, are findings that merit further discussion. The finding that a higher protein intake could be associated with lower mortality also warrants discussion.

The NUTRIC score was the first tool developed specifically to assess nutritional risk in patients admitted to ICU. It has been shown to correlate closely with poor outcomes [16,19], likely related to the inclusion of both age and the SOFA score [20]. Hospitalized older patients are certainly known to suffer more comorbidities, to be at nutritional risk, and to suffer malnutrition, which increase mortality [21]. The degree of organ failure is also linked directly to disease severity and the ability to tolerate nutritional therapy, with greater organ failure potentially causing gastrointestinal complications, gastrointestinal dysfunction and failure, and inadequate absorption, ultimately leading to malnutrition $[22,23]$. This latter issue is compounded by the inadequate provision of nutritional therapy during ICU admission, and perhaps most importantly, by excessive inflammation that may result in poorer nutrient absorption [24,25]. Thus, the association of age, the SOFA score, and the NUTRIC score with the 28-day mortality appears concordant with the pathophysiology of nutrition in critically ill patients.

The EN-PN subgroup was associated with higher 28-day mortality compared with the other subgroups. It is certainly plausible that the delay in starting PN, probably due to their clinical condition (i.e., higher severity) on ICU admission, contributed to the higher mortality rates. However, it is also plausible that these patients experienced higher rates of gastrointestinal dysfunction and failure 
Table 4

Multivariate analysis* of factors associated with 28-day mortality in patients receiving artificial nutritional therapy during ICU stay.

\begin{tabular}{|c|c|c|}
\hline & Hazard ratio (95\% Confidence Interval) & $p$ value \\
\hline Age (years) & $1.023(1.008-1.038)$ & 0.003 \\
\hline Non-trauma patient & $1.965(0.900-4.295)$ & 0.090 \\
\hline SOFA Score & $1.096(1.036-1.160)$ & 0.001 \\
\hline mNUTRIC Score & $1.136(1.025-1.259)$ & 0.015 \\
\hline EN-PN subgroup & $2.368(1.168-4.798)$ & 0.017 \\
\hline Mean $\mathrm{Kcal} / \mathrm{kg} /$ day $^{\text {a }}$ & $1.057(1.015-1.101)$ & 0.008 \\
\hline Mean g protein/kg/day ${ }^{a}$ & $0.507(0.263-0.977)$ & 0.042 \\
\hline Renal Replacement Therapy & $1.742(1.174-2.583)$ & 0.063 \\
\hline Vasoactive drug support & $1.564(0.996-2.456)$ & 0.344 \\
\hline
\end{tabular}

*Model adjusted for potential confounders (i.e., age, patient type, illness severity, length of nutrition therapy, and other significant differences in baseline characteristics, such as sex, comorbidities, Body Mass Index, vasoactive drug support, and renal replacement therapy). SOFA: Sequential Organ Failure Assessment; mNUTRIC: modified Nutrition Risk in the Critically Ill; EN: Enteral Nutrition; PN: Parenteral Nutrition. Significant p values are written in bold.

a During the administration of the whole nutritional therapy or at least in the first 14 days of nutritional therapy.

[24]. We also showed, consistent with contemporary literature, that the use of PN is safe and it does not affect mortality directly [26]. In our cohort, patients receiving very short-term nutrition therapy were more likely to receive PN. This may be explained by the higher proportion of post-surgical patients and lower disease severity within this subgroup.

We also showed that calorie and protein goals, per recommended clinical practice guidelines, were not met in this study [2-4]. This was especially true of patients in whom EN was started from the beginning. Indeed, patients requiring PN after starting EN were more prone to EN-related complications, reflecting their disease severity and difficulty in achieving calorie and protein goals. The latter, together with lower calorie and protein delivery in the EN-PN subgroup, could be related to the higher mortality experienced by those patients. Recent contemporary trials have also reported that these goals were not achieved, with evidence that mean protein amounts of only $0.8-1.1 \mathrm{~g} \mathrm{~kg}^{-1} \mathrm{~d}^{-1}$ were delivered, possibly reflecting the difficulty inherent in providing nutritional therapy to patients with severe critical illnesses [10-13]. In addition, some guidelines claim for a lower caloric delivery (i.e., $11-14 \mathrm{kcal} \mathrm{kg}^{-1} \cdot \mathrm{day}^{-1}$ ) to obese patients, which represent a significant proportion (i.e., 27.1\%) of our patients [27].

We found that higher mean caloric intake may be associated with 28-day mortality during at least the first two weeks of ICU admission: multivariable analysis showed us a higher $5.7 \%$ risk with each mean $\mathrm{Kcal} \cdot \mathrm{Kg}^{-1} \cdot \mathrm{day}^{-1}$. This small effect combined with the caloric goals achieved in this study may seem controversial since the occurrence of complications has been associated with cumulated energy deficit in ICU patients [28]. However, the calorie goal for the critically ill is somewhat controversial given that permissive underfeeding (i.e., $60 \%-70 \%$ of the caloric target) appears to be not only safe but also superior in terms of outcomes in some ICU populations [29]. A full caloric target (i.e., 90\%-100\%) may not be the optimal in the early catabolic phase of an illness, and as such, the caloric target should be individualized based on the patient's nutritional reserve. A caloric intake closer to the target is recommended when there is a risk of malnutrition or when malnutrition and a poor nutritional reserve is present [30]. Most studies to date have also used formulas to calculate calorie goals and have not considered any non-nutritional calorie intake (e.g., glucose, citrate, or propofol), which is not the case of our study [31,32]. Thus, the association of a higher calorie intake with 28-day mortality is probably due to the high calorie goal in patients who needed lower caloric intakes, which may ultimately be associated with overfeeding.
Stress catabolism during the early phase of critical illness results in a loss of protein mass from muscle, contributes to sarcopenia, and ultimately leads to difficult recovery and poorer outcomes [30]. By contrast, a high-protein intake in the early phase of disease may decrease the acute negative protein balance and muscle loss while improving functional recovery [33]. Indeed, the increase in protein synthesis during the catabolic phase combined with adequate protein intake may help to reduce the negative protein balance [34]. This may explain our finding of improved survival with a higher mean protein intake during artificial nutritional therapy.

\subsection{Limitations}

Our study has several limitations, mainly related to its observational design, the heterogeneity of participants, and the difficulty in obtaining the correct macronutrient doses based on clinical practice guidelines during ICU admission. However, the multicenter nature, large sample size, clinical setting (reflecting real practice by ICU physicians delivering nutrition therapy), and long follow-up (14 days after ICU admission) are important strengths. Given the confounding influence of illness severity, patient type, and other potential confounders, we sought to account for these in our analyses. For example, this is important regarding the type of patient: trauma patients in our population experienced lower mortality, which may ultimately be explained by their characteristics (i.e., younger age, fewer comorbidities, and a better nutritional statuses). We also stratified patients by the type of artificial nutritional therapy to identify differences among the different routes. Our results regarding mean calorie and protein intakes come to the fore as areas that merit further analysis. We have an analysis planned to assess the adequacy of when macronutrient intake occurred. The novelty of this research is in the combination of all these methods together with all the combined reported observations in the multivariable analysis.

\section{Conclusions}

In summary, we showed that higher nutritional risk, greater organ failure severity, and older age are nutrition-related factors that may be associated with increased mortality. Regarding the type of nutritional therapy received, those patients needing PN after starting EN may represent a high mortality risk subgroup, probably due to greater illness severity and the presence of gastrointestinal failure, which also causes problems in giving appropriate nutritional therapy. Finally, we showed that higher mean protein intake and mean caloric intake during the first weeks of ICU stay may be associated with better and worst outcomes respectively. These findings, in turn, indicate that macronutrient delivery may have a prominent role in ICU outcomes.

\section{Funding}

The present research was granted by the Spanish Society of Nutrition and Metabolism (SENPE; Sociedad Española de Metabolismo y Nutrición).

\section{Conflict of interest}

All the authors declare that they have no conflicts of interest in regard to the subject of this manuscript.

\section{Authors' contributions}

JCLD, TGC and LSG conceived, designed and coordinated the study. All authors collected the data during the study period and 
participated in the revision. TGC, JCLD and JTC performed the statistical analysis and developed the first draft of the manuscript. All authors were involved in the interpretation of the results, critically revised the manuscript and approved the final version.

\section{Acknowledgments}

We thank all the members of the ENPIC Study Group who participated in the meeting held in Madrid on October 26-27, 2017 for their contribution to a consensus in drafting the database used in the present study. We also thank the Spanish Society of Nutrition and Metabolism (SENPE; Sociedad Española de Metabolismo y Nutrición) for funding support and CERCA Programme / Generalitat de Catalunya for institutional support.

\section{Appendix A. Supplementary data}

Supplementary data to this article can be found online at https://doi.org/10.1016/j.clnesp.2021.11.018.

\section{References}

[1] Preiser JC, Ichai C, Orban JC, Groeneveld AB. Metabolic response to the stress of critical illness. Br J Anaesth 2014;113:945-54.

[2] Weimann A, Braga M, Carli F, Higashiguchi T, Hübner M, Klek S, et al. ESPEN guideline: clinical nutrition in surgery. Clin Nutr 2017;36:623-50.

[3] Singer P, Blaser AR, Berger MM, Alhazzani W, Calder PC, Casaer MP, et al. ESPEN guideline on clinical nutrition in the intensive care unit. Clin Nutr 2019;38:48-79.

[4] Kumpf VJ, de Aguilar-Nascimento JE, Diaz-Pizarro Graf JI, Hall AM, McKeever L, Steiger E, et al. FELANPE; American society for parenteral and enteral nutrition. ASPEN-FELANPE clinical guidelines. JPEN - J Parenter Enter Nutr 2017;41: 104-12.

[5] Lee ZY, Heyland DK. Determination of nutrition risk and status in critically ill patients: what are our considerations? Nutr Clin Pract 2019;34:96-111.

[6] McClave SA, Martindale RG, Rice TW, Heyland DK. Feeding the critically ill patient. Crit Care Med 2014;42:2600-10.

[7] Lew CCH, Yandell R, Fraser RJL, Chua AP, Chong MFF, Miller M. Association between malnutrition and clinical outcomes in the intensive care unit: a systematic review. JPEN - J Parenter Enter Nutr 2017;41:744-58.

[8] Lambell KJ, Tatucu-Babet OA, Chapple LA, Gantner D, Ridley EJ. Nutrition therapy in critical illness: a review of the literature for clinicians. Crit Care 2020;24:35.

[9] Servia-Goixart L, Lopez-Delgado JC, Grau-Carmona T. Evaluation of the degree of adherence to the nutritional recommendations in critical care patients. Nutr Hosp 2019;36:510-6.

[10] Casaer MP, Mesotten D, Hermans G, Wouters PJ, Schetz M, Meyfroidt G, et al. Early versus late parenteral nutrition in critically ill adults. N Engl J Med 2011;365:506-17.

[11] Singer P, Anbar R, Cohen J, Shapiro H, Shalita-Chesner M, Lev S, et al. The tight calorie control study (TICACOS): a prospective, randomized, controlled pilot study of nutritional support in critically ill patients. Intensive Care Med 2011;37:601-9.

[12] Doig GS, Simpson F, Sweetman EA, Finfer SR, Cooper DJ, Heighes PT, et al. Early PN Investigators of the ANZICS Clinical Trials Group. Early parenteral nutrition in critically ill patients with short-term relative contraindications to early enteral nutrition: a randomized controlled trial. J Am Med Assoc 2013;309:2130-8.

[13] Reignier J, Boisramé-Helms J, Brisard L, Lascarrou JB, Ait Hssain A, Anguel N, et al. Enteral versus parenteral early nutrition in ventilated adults with shock: a randomised, controlled, multicentre, open-label, parallel-group study (NUTRIREA-2). Lancet 2018;391:133-43.
[14] Veldsman L, Richards GA, Blaauw R. The dilemma of protein delivery in the intensive care unit. Nutrition 2016:32:985-8.

[15] Ridley EJ, Davies AR, Parke R, Bailey M, McArthur C, Gillanders L, et al. Supplemental Parenteral Nutrition Clinical Investigators. Supplemental parenteral nutrition versus usual care in critically ill adults: a pilot randomized controlled study. Crit Care 2018;22:12.

[16] Gonzalez MC, Bielemann RM, Kruschardt PP, Orlandi SP. Complementarity of NUTRIC score and Subjective Global Assessment for predicting 28-day mortality in critically ill patients. Clin Nutr 2019:38:2846-50.

[17] Cederholm T, Barazzoni R, Austin P, Ballmer P, Biolo G, Bischoff SC, et al. ESPEN guidelines on definitions and terminology of clinical nutrition. Clin Nutr 2017;36:49-64.

[18] Lederer DJ, Bell SC, Branson RD, Chalmers JD, Marshall R, Maslove DM, et al. Control of confounding and reporting of results in causal inference studies. Guidance for authors from editors of respiratory, sleep, and critical care journals. Ann Am Thorac Soc 2019;16:22-8.

[19] Rahman A, Hasan RM, Agarwala R, Martin C, Day AG, Heyland DK. Identifying critically-ill patients who will benefit most from nutritional therapy: further validation of the "modified NUTRIC" nutritional risk assessment tool. Clin Nutr 2016;35:158-62.

[20] de Vries MC, Koekkoek WK, Opdam MH, van Blokland D, van Zanten AR. Nutritional assessment of critically ill patients: validation of the modified NUTRIC score. Eur J Clin Nutr 2018;72:428-35.

[21] Cerri AP, Bellelli G, Mazzone A, Pittella F, Landi F, Zambon A, et al. Sarcopenia and malnutrition in acutely ill hospitalized elderly: prevalence and outcomes. Clin Nutr 2015;34:745-51.

[22] Reintam A, Parm P, Kitus R, Starkopf J, Kern H. Gastrointestinal failure score in critically ill patients: a prospective observational study. Crit Care 2008;12:R90.

[23] Fagoni N, Piva S, Marino R, Chiarini G, Ferrari D, Grespi E, Bertuetti R, Barbieri S, Latronico N, Rasulo F. The IN-PANCIA study: clinical evaluation of gastrointestinal dysfunction and failure, multiple organ failure, and levels of citrulline in critically ill patients.

[24] Jensen GL, Mirtallo J, Compher C, Dhaliwal R, Forbes A, Grijalba RF, et al. Adult starvation and disease-related malnutrition: a proposal for etiology-based diagnosis in the clinical practice setting from the International Consensus Guideline Committee. JPEN - J Parenter Enter Nutr 2010;34:156-9.

[25] Padar M, Starkopf J, Uusvel G, Reintam Blaser A. Gastrointestinal failure affects outcome of intensive care. J Crit Care 2019;52:103-8.

[26] Elke G, van Zanten AR, Lemieux M, McCall M, Jeejeebhoy KN, Kott M, et al. Enteral versus parenteral nutrition in critically ill patients: an updated systematic review and meta-analysis of randomized controlled trials. Crit Care 2016;20:117.

[27] Serón Arbeloa C, Martínez de la Gándara A, León Cinto C, Flordelís Lasierra JL, Márquez Vácaro JA. Recommendations for specialized nutritional-metabolic management of the critical patient: macronutrient and micronutrient requirements. Metabolism and nutrition working group of the Spanish society of intensive and critical care medicine and coronary units (SEMICYUC). Med Intensiva (Engl Ed). 2020;44(Suppl 1):24-32.

[28] Villet S, Chiolero RL, Bollmann MD, Revelly JP, Cayeux RNMC, Delarue J, et al. Negative impact of hypocaloric feeding and energy balance on clinical outcome in ICU patients. Clin Nutr 2005;24:502-9.

[29] Arabi YM, Tamim HM, Dhar GS, Al-Dawood A, Al-Sultan M, Sakkijha MH, et al. Permissive underfeeding and intensive insulin therapy in critically ill patients: a randomized controlled trial. Am J Clin Nutr 2011;93:569-77.

[30] Weijs PJ, Looijaard WG, Dekker IM, Stapel SN, Girbes AR, Oudemans-van Straaten HM, et al. Low skeletal muscle area is a risk factor for mortality in mechanically ventilated critically ill patients. Crit Care 2014;18:R12.

[31] Charrière M, Ridley E, Hastings J, Bianchet O, Scheinkestel C, Berger MM. Propofol sedation substantially increases the caloric and lipid intake in critically ill patients. Nutrition 2017;42:64-8.

[32] New AM, Nystrom EM, Frazee E, Dillon JJ, Kashani KB, Miles JM. Continuous renal replacement therapy: a potential source of calories in the critically ill. Am J Clin Nutr 2017;105:1559-63.

[33] Allingstrup MJ, Esmailzadeh N, Wilkens Knudsen A, Espersen K, Hartvig Jensen T, Wiis J, et al. Provision of protein and energy in relation to measured requirements in intensive care patients. Clin Nutr 2012;31:462-8.

[34] Zusman O, Theilla M, Cohen J, Kagan I, Bendavid I, Singer P. Resting energy expenditure, calorie and protein consumption in critically ill patients: a retrospective cohort study. Crit Care 2016;20:367. 